\title{
Educação 4.0 e o contexto do ensino remoto: percepção dos alunos do curso de pedagogia
}

\author{
Education 4.0 and the context of remote teaching: pedagogy course students' \\ perception
}

\author{
Andréa Kochhann $^{1 *}$, Andrey de Castro $^{1}$, Francisco Alberto Severo', Nay Borges ${ }^{1}$
}

\begin{abstract}
RESUMO
A pandemia de SARS-Cov-19 (covid-19) afetou o mundo em diversos setores, inclusive educacional, impulsionando esta pesquisa pela problematização "como os alunos do curso de Pedagogia da UEG do Campus Oeste, sede São Luís de Montes Belos percebem o ensino remoto no contexto pandêmico?". O objetivo geral é analisar a percepção dos alunos sobre o ensino remoto na pandemia e os específicos: compreender a relação da educação 4.0 e o ensino remoto; contextualizar a Universidade Estadual de Goiás, Câmpus Oeste, sede São Luís de Montes Belos; analisar a percepção dos alunos quanto ao ensino aprendizagem no contexto pandêmico. Esta pesquisa é aplicada, exploratória, quali-quantitativa, documental, bibliográfica e com questionários estruturados aplicados à alunos do curso de Pedagogia do $1^{\circ}$ ao $4^{\circ}$ ano, do ano de 2020. A pesquisa revela impactos da pandemia no processo de ensino e aprendizagem e a improtância do Ensino remote, acesso a tecnologias da informação e comunicação e qualidade de internet, como pontos sensíveis a Educação 4.0, cuja essência está na tecnologia, acelerando um processo de repensar e de ruptura como uma concepção de educação tradicional para uma tecnológica.
\end{abstract}

Palavras-chave: Pandemia; Ensino Remoto; Educação 4.0; Ensino-aprendizagem.

\begin{abstract}
The SARS-Cov-19 (covid-19) pandemic has affected the world in various sectors, including education, driving this research by the problematization "how do students of the Pedagogy course at UEG's West Campus, São Luís de Montes Belos headquarters perceive remote teaching in the pandemic context?". The general objective is to analyze the students' perception of remote teaching in the pandemic and the specific ones are: to understand the relationship between education 4.0 and remote teaching; to contextualize the Universidade Estadual de Goiás, Câmpus Oeste, São Luís de Montes Belos; to analyze the students' perception of teaching learning in the pandemic context. This research is applied, exploratory, qualiquantitative, documental, bibliographic and with structured questionnaires applied to the students of the Pedagogy course from the 1st to the 4th year, of the year 2020. The research reveals impacts of the pandemic in the teaching and learning process and the improtancy of remote teaching, access to information and communication technologies and internet quality, as sensitive points to Education 4.0, whose essence is in technology, accelerating a process of rethinking and rupture as a conception of traditional education for a technological one.
\end{abstract}

Keywords: Pandemic; Remote Learning; Education 4.0; Teaching-Learning.

\footnotetext{
${ }^{1}$ Universidade Estadual de Goiás (UEG).

*E-mail: andreakochhann@yahoo.com.br
} 


\section{INTRODUÇÃO}

Este estudo é oriundo das inquietações que permeiam o processo de adaptabilidade no processo de ensino e aprendizagem frente ao contexto pandêmico da SARS-Cov-19, anunciado como pandemia global pela Organização Mundial da Saúde (OMS) no dia 11 de março de 2020, para tal a OMS iniciou e incentivou inúmeras recomendações sanitárias para evitar a proliferação pandêmica que resultou em medidas de fechamentos, distanciamentos e isolamento social dada a representativa gravidade do vírus. Estas medidas profiláticas, redefiniram o modo de viver e ser sociedade, o que interferiu diretamente em vários setores, título de exemplificação tem-se: saúde, econômico, políticos, sociais e educacionais em todo o mundo e é acerca da influência da covid-19 no sistema educacional, especialmente quanto ao processo de ensino aprendizagem que a escrita se debruça.

As aulas presenciais foram suspensas e a modalidade de ensino remoto ganha força, impulsionando uma concepção de educação mediada pelas tecnologias contemporâneas digitais. Nesse panorama discute-se a aproximação da tecnologia ao ensino aprendizagem frente a iminência ou emergência de uma Educação 4.0, assim recorreu-se às aulas remotas, no curso de Pedagogia, da UEG, Câmpus Oeste, sede São Luís de Montes Belos - GO como amostra, no intento de vislumbrar a influência da pandemia na educação superior. Considera-se que as novas mídias, a globalização e até mesmo o perfil do estudante remontam a necessidade de reconfiguração dos modelos de gestão do ensino nas universidades conforme Fuhr (2019).

Para subsidiar tais intenções lança-se mão de uma pesquisa de natureza aplicada, exploratória quanto aos seus objetivos, de abordagem quali-quantitativa conforme Gatti (2004, p.4), pois há nessa abordagem metodológica “[...] o esforço de reflexão do pesquisador para dar sentido ao material levantado e analisado" e de acordo com Gil (2008) quanto aos procedimentos e métodos de coleta de dados documental e bibliográfico com uso de questionários estruturados em escala likert aos alunos que cursam de $1^{\circ}$ a $4^{\circ}$ ano de Pedagogia, em 2020.

Salienta-se que o cenário de pesquisa abarca a opção do ensino remoto utilizado na Universidade Estadual de Goiás (UEG), os dados foram coletados no mês de março de 2021. Foram investigadas 4 turmas do curso de Licenciatura em Pedagogia num total de 148 matriculados, dos quais 6 trancaram a matrícula em períodos diversos (segundo, 
quarto, sexto e oitavo períodos visto que, neste câmpus, o segundo semestre letivo de 2020 se encerra em março de 2021, devido às alterações no calendário acadêmico).

Esta pesquisa tem por objetivo geral analisar a percepção dos discentes do curso de Pedagogia do Campus Oeste, sede São Luís de Montes Belos (SLMB), acerca do ensino remoto no contexto pandêmico. De modo, a instigar uma possível reflexão acerca da viabilidade da reestruturação da educação, frente aos moldes da Educação 4.0. No intuito de possibilitar a investigação propõe-se os seguintes objetivos específicos: compreender a relação da educação 4.0 e o ensino remoto; contextualizar a universidade Câmpus Oeste, sede São Luís de Montes Belos e o ensino remoto, bem como analisar a percepção dos alunos quanto ao ensino aprendizagem no contexto pandêmico. Esses objetivos norteiam a estruturação e a lógica da pesquisa.

\section{Educação 4.0 e Ensino remoto: encontros e contradições}

O mundo está passando por alterações antes não previstas, o ritmo dessa alteração é tão acelerado quanto às substituições das mesmas, nas palavras de Philbech (2019, p. 31) “[...] a Quarta Revolução Industrial já começou.[...]” Mundo afora os sistemas são interconexos, e o impacto dessa conectividade e mudanças aligeiradas em níveis globais, não se mostra apenas nos setores industriais “[...] em um mundo tecnologicamente saturado e interdependente, estamos necessitados de liderança de sistemas." (idem, 2019, p. 32)

Diálogos e principalmente a cooperação se fazem de suma importância em vários domínios, ou seja, há a imperatividade de desenvolver um trabalho conjunto, no qual "[...] a liderança nesse processo deve inspirar a sociedade global a trabalhar em conjunto para gerar mudanças sustentáveis, positivas e sistêmicas, e a desenvolver as plataformas colaborativas para poder fazer isso.” (PHILBECH, 2019, p. 32). É muito importante compreender o papel da educação nesse contexto, pois

Não existe lugar mais importante para moldar o futuro da sociedade do que a sala de aula. Como líderes da criação da aprendizagem, todos os que se dedicam à educação têm papel determinante no desenvolvimento sistêmico da sociedade e no futuro coletivo global. (PHILBECH, 2019, p. 32) 
A educação 4.0 parte da lógica do desenvolvimento sistêmico, que está envolto a uma perspectiva de educação mediada pelas tecnologias contemporâneas, reflexo da sociedade da informação alicerçada nos moldes da Quarta Revolução Industrial, ou como é reconhecida por alguns Revolução 4.0. Essa revolução é sentida de diversas formas, encontrando na educação um dos espaço determinantes, para que a sociedade se desenvolva no contexto 4.0.

O que chama a atenção é a escala, o escopo e a velocidade com que as tecnologias e/ou desenvolvimento tecnológico se altera, em distribuição, valores, formas e sentidos. Assim, é preciso refletir sobre as transformações oriundas desse cenário, como forma de concebermos as organizações, o trabalho em equipe, as relações sociais, políticas e econômicas, etc. Portanto, é impossível fugir dos impactos 4.0 nas estruturas e relações sociais de acordo com Philbech (2019).

A Educação 4.0 concebe que "[...] a mensagem crítica é reforçar o uso da colaboração, a inclusão das várias partes interessadas, a evolução disciplinar cruzada e o pensamento sistêmico.” (PHILBECH, 2019, p. 33). Subentende-se que, nesse cenário é necessário haver cooperação entre instituições, departamentos, redes, disciplinas, etc. Uma vez que, nesse contexto de revolução que envolve visão de futuro, evolução de modelos de negócios, matemática, dentre outros, ninguém consegue seguir sozinho, ou seja, gerenciar sozinho. "Daí a importância de levar e espalhar a mensagem, para que cause a mudança no mais crucial dos pontos, isto é, no ensino superior." (PHILBECH, 2019, p. 33)

Em geral, ao pensar a Universidade, tem-se a ideia de um local de ensino pautado numa disciplina específica, para fins diversos, social, histórico e não menos importante o profissional. “[...] As universidades são portadoras de conhecimento, mas seus papéis estão mudando.” (PHILBECH, 2019, p. 33) Neste lócus o estudante, deixa de ser um mero receptor de informações, a exemplo de uma simples máquina e a universidade, mera transmissora, mas ambos se inserem como elementos sistêmicos constitutivos da Indústria 4.0.

No contexto educacional é preciso haver diálogo aberto, para que o pensamento crítico ganhe espaço de modo que, segundo Bertoline (2019, p. 60) "A autonomia não se desenvolve com professores que se colocam como figuras de autoridade em sala de aula, conforme ocorre no modelo tradicional. O mesmo ocorre com a criatividade, que não se desenvolve com tarefas padronizadas e repetitivas.". 
$\mathrm{Na}$ visão 4.0 os profissionais da educação devem primar pela criatividade e adaptabilidade quanto ao uso das Tecnologias da Informação e Comunicação (TIC's). Em se tratando desse contexto, Vieira $(1989$, p. 11) alerta que "[...] em qualquer sociedade, seja ela conservadora ou progressista, a educação superior constitui um bem cultural acessível a uma minoria e a universidade é privilégio de poucos.”. Parte-se dessa fala, e dos pontos supracitados como o ensino universitário reflete as demandas da Educação 4.0 no contexto da pandemia e suas influências no processo de ensino aprendizagem.

Para início de conversa faz-se necessário refletir sobre a fala de Vieira (1989, p. 13) "um dos entraves ao conhecimento da universidade em nossos dias reside na dificuldade de discernir-se entre o que se chamou de "o fazer e o fazer de conta" [...]" Com base nesse ponto indaga-se o momento do ensino, impulsionado/vivenciado na pandemia do Covid-19. É preciso considerar nesses escritos, os aspectos de acesso, dificuldades, riscos, novas formulações e aprendizados, bem como, a influência/vivência da Educação 4.0 no ensino superior.

Nesse sentido, cabe às instituições de ensino, em especial as de ensino superior, entender seu papel social de responsáveis pela formação dos profissionais adequados às necessidades vigentes. De modo a propiciar um aprendizado que vá para além da sala de aula, recorrendo a mediação tecnológica por meio de plataformas e mídias digitais utilizando-se de vídeos, plataformas, blogs, aplicativos, dentre outras tecnologias. Uma vez que, na crescente ascensão da Educação 4.0, nenhum setor pode abrir mão da tecnologia para evoluir de acordo com Rasquilha e Veras (2019).

Diante do desenvolvimento sistêmico e de um coletivo global, a Revolução 4.0 apresenta dimensões complexas e inúmeros questionamentos acerca das vantagens ou desvantagens quanto a sua efetivação “[...] por enquanto, nós não podemos dar todas as respostas. Mas continue perguntando, porque, cada vez que vocês perguntam, esta máquina aprende e se capacita para dar mais respostas." (FIGUEIREDO, 2019, p. 14). Portanto, é indiscutível que a tecnologia está permeando os modos de viver e laborar, logo, a dimensão tecnológica torna-se intrínseca ao ser humano.

Bezerra et al (2020) aponta que o Ensino remoto no Brasil tem caráter emergencial com foco na situação de crise, o que permite pensar o ensino remoto não como elemento da Educação 4.0, mas como uma modalidade que se aproxima dessa vertente por recorrer ao uso das tecnologias para mediação pedagógica. A Educação 4.0 pode ser concebida como modelo de educação no qual a tecnologia ganha espaço, a 
linguagem computacional e a inteligência artificial, que são possibilidades inovadoras para um ensino pautado no processo do aprender fazendo ou "learning by doing" de acordo com Fuhr (2019).

$\mathrm{Na}$ Era digital, a sociedade da informação e a cybercultura são expressões dessa realidade e em sentido pedagógico são produto da Quarta Revolução Industrial. A Educação 4.0 se funda como educação tecnológica podendo ser representada por modalidades de ensino como a Educação a Distância, cuja essência é a mediação tecnológica. Já o Ensino remoto possui tônica situacional e emergencial que o distancia do modelo 4.0 pela questão da crise endêmica, mas se aproxima por requerer adaptação dos profissionais e educandos para uma realidade/modalidade de ensino norteado na tecnopedagogia, ou seja, o aproveitamento das tecnologias digitais de informação e comunicação (TDIC), para viabilizar as práticas pedagógicas conforme Fuhr (2019). Neste cenário é imprescindível o uso tecnológico para sua efetivação dada a impossibilidade do ensino presencial.

A Educação 4.0 sinaliza para uma inovação pedagógica, na qual as mudanças da era da informação digital do século XXI, denotam o professor enquanto orquestrador de múltiplas informações, que serão destinadas aos educandos. Neste lócus prescinde aos mesmos, serem autores do conhecimento, por via do desenvolvimento de habilidades e competências correspondente a sociedade 4.0 aponta Führ (2018). Na educação em redes o ensino remoto se aproxima da Educação 4.0, por possibilitar a continuidade do desenvolvimento da universidade da pesquisa e do ensino, ainda que essa modalidade seja situacional.

O cenário pandêmico do ensino remoto acirrou o fomento de uma vivência virtual, e como denota Levy (2014) a cibercultura, tal como a mediação tecnológica o demandou inúmeras inovações pedagógicas que envolvem o domínio de uma linguagem tecnopedagógica segundo Führ (2018) impelindo a reflexão sobre as possibilidades e necessidade de formação. Mas sem prescindir de analisar e considerar criticamente, as questões materiais de acesso e distribuição da tecnologia, sem as quais a educação não se faz e nem se democratiza por meio tecnológico, ao passo que, poderia ser um abismo e não uma ponte ao conhecimento.

A conjuntura de crise impulsionado pela pandemia, impulsionou o uso das tecnologias no âmbito educacional. No tocante ao Ensino Superior o uso do ensino remoto explicitou potencialidades e desafios à Educação 4.0, concepção de educação dentro da 
Quarta revolução industrial que abarca a visão da educação essencialmente sistêmica e tecnologia, da vivência do processo ensino aprendizagem a mediação. Assim, ainda que o ensino remoto resulte no uso das tecnologias da informação e comunicação na educação essa modalidade não é reflexo direto da Educação 4.0, pois seu caráter é emergencial com vista a conjunturalmente substituir o ensino presencial dada a sua impossibilidade situacional diferente de uma perspectiva de educação a distância na qual a filosofia é o usufruto tecnológico como logística e operacionalização educacional.

\section{Universidade e ensino remoto: contexto e apropriações}

As origens das universidades remontam a Itália do século XI quando nascera a Universidade de Bolonha (1088). O termo universidade usual e amplamente difundido advém da expressão "universitas magistrorum et scholarium", comunidade de mestres e estudiosos, aponta César (2013). Portanto, o nascimento da universidade está diretamente vinculado à produção e circulação de conhecimento, entende-se que "a universidade tem como objetivo a produção e a disseminação da ciência, da cultura e da tecnologia." (CUNHA, 1989, p. 69).

A universidade só pode ser entendida à luz da indissociabilidade expressa na Lei de Diretrizes e Bases da Educação Nacional - LDB - Lei no 4.024/1961 por traduzir o espírito investigativo, produtivo e formativo da universidade, enquanto construto histórico que responde a dimensões políticas, econômicas e sociais.

Com vista a atender as demandas da pesquisa faz-se-á um recorte quanto ao surgimento da UEG (Universidade Estadual de Goiás) que se deu conforme Kochhann (2013, p. 85) em razão de um

Projeto de Lei na Assembleia Legislativa, depois pela Lei n. 8772, de 15 de janeiro de 1980. Essa Lei delegava ao Poder Executivo autorização para criar a Universidade do Estado de Goiás com sede em Anápolis, sob a forma de Fundação. A partir do "sonho" de construção de um projeto de universidade enraizada em todas as microrregiões goianas, resulta a criação da UEG, com a transformação da UNIANA com a incorporação de 28 autarquias isoladas, mantidas pelo Poder Público Estadual.

Conforme a autora, somente em 1999 esse processo foi oficializado pelo então governador, por via da Lei n. 13. 456 em 16 de abril do ano supracitado. Salienta-se que, 
só após passados 10 anos, a mesma se tornou autarquia, por via da "Lei n. 16. 272 de 30 de maio de 2008." (KOCHHANN, 2013, p. 87). No ano de 2012 a Universidade Estadual de Goiás, contava com 42 Unidades Universitárias, em distintos municípios do estado do Goiás.

\begin{abstract}
Anápolis: Anápolis, Aparecida de Goiânia, Caldas Novas, Campos Belos, Ceres, Crixás, Edéia, Formosa, Goianésia, Goiânia, Goiás, Inhumas, Ipameri, Iporá, Itaberaí, Itapuranga, Itumbiara, Jaraguá, Jataí, Jussara, Luziânia, Minaçu, Mineiros, Morrinhos, Niquelândia, Palmeiras de Goiás, Pirenópolis, Pires do Rio, Porangatu, Posse, Quirinópolis, Sanclerlândia, Santa Helena de Goiás, São Luís de Montes Belos, São Miguel do Araguaia, Senador Canedo, Silvânia, Trindade e Uruaçu. (KOCHHANN, 2013, p. 87-88)
\end{abstract}

A UEG, apresenta-se uma universidade pública com vistas à interiorização que impulsiona a educação e concomitante a melhoria do mercado profissional. Nesse sentido nasce a UEG Câmpus Oeste, tendo como sede a cidade de São Luís de Montes Belos, cuja origem $^{2}$ remonta a década de 1973 com as primeiras manifestações em prol da implantação do ensino superior no local, pleiteada pela Associação Montebelense do Ensino Superior (AMES). O Câmpus funciona desde 1993, com a instituição do curso de Pedagogia Regular. Tendo formado profissionais em diferentes áreas

(Pedagogia Regular e Parceladas, Letras Regular, Geografia, Biologia, História, Educação Física (Parceladas), de Bacharelado (Zootecnia), de Sequenciais (Gestão Pública e Agronegócio) de Tecnólogos (em Laticínios) e por formar profissionais em Pós-Graduação Lato Sensu (Psicopedagogia, Docência Universitária, Língua Portuguesa e Literatura Brasileira e Bovinocultura de Leite). (UEG, 2021, s/p)

Logicamente muito tempo se passou, e de lá até o ano de 2021. Muita coisa mudou, entretanto, a ideia de analisar sobre a origem e importância da UEG, se deve ao fato de que, nesses escritos, a intenção é abordar conceitos quanto a importância das universidades, seu papel e o ensino no presente momento. Atualmente essa sede conta com 4 cursos, tais sejam: Pedagogia, Letras, Medicina Veterinária e Zootecnia.

A pandemia da Covid -19 requereu do sistema educativo nacional mudanças as quais se inserem a substituição das aulas presenciais pela modalidade de ensino modo

\footnotetext{
2 http://www.campusoeste.ueg.br/conteudo/9589_historia
} 
mediado pelas tecnologias digitais conforme a portaria 343 do Ministério da Educação (MEC). Essa diretriz impactou diretamente a organização e o funcionamento das universidades, não distante a UEG e o próprio Câmpus Oeste, sede São Luís de Montes Belos.

A educação em todos os seus níveis passou à situação de emergência, implicando inovação e adequação urgentes ao contexto da pandemia impulsionado por essa modalidade de Ensino Remoto nas universidades brasileiras como possibilidade de continuidade e desenvolvimento das atividades acadêmicas, seja na pesquisa ou no ensino, sendo esse último severamente afetado por essa modalidade. Segundo Ali (2020) instaurou-se uma atmosfera de incerteza pedagógica capaz de comprometer a equidade educacional.

Considerando as normativas do Governo Federal, por meio do DECRETO N ${ }^{\circ}$ 9.634, de 13 de março de 2020, asseverou-se quanto à necessidade de suspender toda e qualquer atividade não essencial que aglomere pessoas durante a pandemia do COVID19, tal decreto afetou inúmeros setores da sociedade. Estabeleceu-se por meio do mesmo a necessidade do isolamento social, diante disso, as aulas nas instituições de ensino país afora foram suspensas. A Fim de não perder o ano letivo e por via de adequação de calendário, algumas instituições optaram pelo sistema de aulas remotas, que se difere no presencial bem como do EAD, nesse sentido, salienta-se que, no modelo emergencial remoto, o docente tem a pode ofertar suas aulas com o mínimo de perda de conteúdo em plataformas digitais, de modo que os alunos sejam participantes síncronos.

Fazendo uma retrospectiva em termos legais, apresenta-se a data de 17 de março de 2020, como sendo aquela em que o CEE aprovou a Resolução CEE/CP nº 02/2020 que discorria sobre "o regime especial de aulas não presenciais no Sistema Educativo do Estado de Goiás, como medida preventiva à disseminação do COVID-19”. Esta proposta viabiliza a possibilidade de oferta de educação no que diz respeito ao sistema educativo do estado de Goiás de modo a dar-lhe a permissibilidade para implementar o regime especial de aulas não presenciais. Tal prerrogativa foi acolhida pela Reitoria da UEG que no dia 25 de março de 2020, e a mesma publicou a Instrução Normativa $n^{\circ}$ 80/2020, que enquanto ato normativo norteou os principais elementos para implementação do PEEA, com foco na oferta de aulas presenciais mediadas por recursos tecnológicos.

Mediante a situação vivenciada a UEG criou um manual de sistemas de aulas remotas com o intuito de orientar professores a alunos quanto a sua conduta no modelo 
emergencial remoto. Enfatiza-se que o manual apontava possíveis plataformas a serem utilizadas, mas a instituição deixou a cargo dos professores decidirem como ofertaram suas aulas, ou seja quais caminhos tomariam. Justifica-se que a universidade ficou apenas uma semana sem aulas para adequação e que com base em pesquisas realizadas nos campos, desenvolveu programas de subsídio para fomentar o acesso dos alunos às aulas, a exemplo da bolsa conectividade, formação pela UEGTV nas segundas-feiras, migração dos eventos presenciais para o campo remoto, etc.

Ensino remoto e ensino-aprendizagem: percepção dos alunos do curso de pedagogia

A pandemia de covid-19 impactou todos os setores sociais. Não obstante o sistema educacional foi posto em um cenário de emergência e urgência de revisão das propostas e ações pedagógicas, na tentativa de evitar a interrupção dos processos de ensino-aprendizagem, isto em decorrência das diretrizes de combate à pandemia que incluíam o fechamento das instituições. Assim, para compreender a relação da pandemia com o ensino remoto, adotado por diferentes universidades, e a convergência desses fatores no processo ensino-aprendizagem dos estudantes do nível superior, tomou-se a Universidade Estadual de Goiás Câmpus Oeste, sede São Luís de Montes Belos, como amostra desse fenômeno conjuntural pandêmico que foi o ensino remoto.

Este estudo é de natureza quali-quantitativo com vistas a ancorar-se na validação dos dados quantitativos obtidos e na análise qualitativa possibilitada de modo a "desmistificar representações, preconceitos, "achometros", sobre fenômenos educacionais, construídos apenas a partir do senso comum do cotidiano, ou do marketing" (GATTI, 2004, p. 26). Para tal, utilizou-se como procedimento de coleta de dados um questionário estruturado com base na escala Likert, na qual a mensuração dos dados se dá pela análise multi-item das atitudes de um grupo, assim a escala se configura um instrumento científico de observação e mensuração de fenômenos sociais idealizada com a finalidade de medir as atitudes por meio das opiniões de forma objetiva (LIKERT, 1932).

O público alvo da pesquisa foram os alunos do curso de Pedagogia. $\mathrm{O}$ formulário foi disposto nos grupos dos componentes curriculares "Pedagogia em Espaços Não Escolares; Didática; Corpo Cultura e Expressividade e Métodos de Produção do Trabalho Científico em Educação", componentes ofertados no $1^{\circ}, 2^{\circ}, 3^{\circ}$ e $4^{\circ}$ anos do curso de 
Pedagogia. Nas quais, salienta-se que, pode haver a participação de alunos de outros cursos, por estarem na modalidade, "núcleo livre" a exemplo da disciplina Pedagogia em Espaços não Escolares.

O curso de Pedagogia tem 142 alunos matriculados, desse total, 80 participaram da pesquisa. Destes, 78 são do curso de Pedagogia e 2 do curso de Zootecnia. O público pesquisado foi em sua maioria feminino, $96,3 \%$ para 3,7 \% masculino. O que, mesmo não estando em foco neste trabalho, não deixa de chamar a atenção, dado as especulações quanto ao curso de Pedagogia ser um curso mais voltado para mulheres. Ressalta-se ainda que, a amostra é composta por elementos de todos os anos do curso de formação em Pedagogia.

Os partícipes da pesquisa tem em sua maioria, entre 21 a 25 anos de idade, um total de 43,8 \% declararam ter essa faixa etária, seguidos de: 18,8 \%, 18 a 20 anos; 10\%, 26 a 30 anos; 10\%, 31 a 35 anos; 7,5 \%, 41 a 45 anos; $5 \%, 46$ a 50 anos; 3,7 \%, 36 a 40 anos e 1,2 declararam ter entre 51 e 55 anos de idade, caracterizando um público com idades bem alternadas. A fim de possibilitar uma análise mais fidedigna dos dados obtidos, recorreu-se à utilização de eixos, sendo eles: pandemia e educação; ensino remoto e Educação 4.0.

\section{Pandemia e educação}

O eixo pandemia e educação abarca as questões 1 a 5 nas quais questiona-se a percepção dos partícipes quanto à influência da pandemia na realidade da Educação no Ensino Superior.

Figura 1 - O contexto pandêmico da Covid-19, alterou a perspectiva de educação no ensino superior?

1. O contexto pandêmico da Covid-19, alterou a perspectiva de educação no ensino superior? 80 respostas
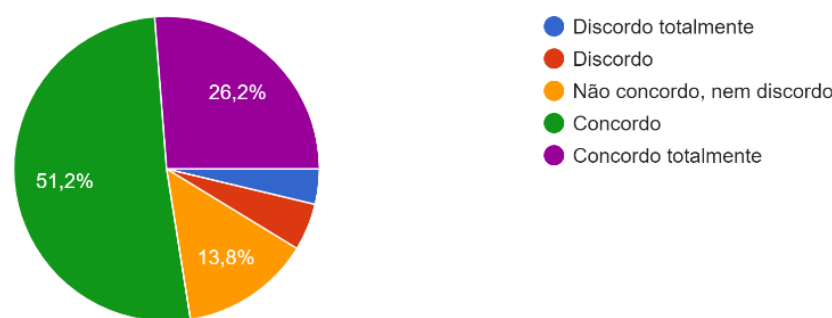

Fonte: Kochhann, Castro, Severo e Borges. (2021) 
Figura 2 - Você considera que a pandemia prejudicou a qualidade do Ensino aprendizagem no ensino superior?

2. Você considera que a pandemia prejudicou a qualidade do ensino aprendizagem no ensino

superior?

80 respostas

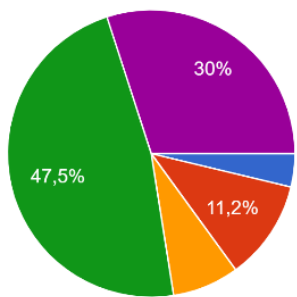

Discordo

Não concordo, nem discordo

Concordo

Concordo totalmente

Fonte: Kochhann, Castro, Severo e Borges. (2021)

Figura 3 - A pandemia da covid-19 modificou a realidade do Campus Oeste São Luís de Montes Belos?

3. A pandemia da covid-19 modificou a realidade do Campus Oeste São Luis de Montes Belos? 80 respostas

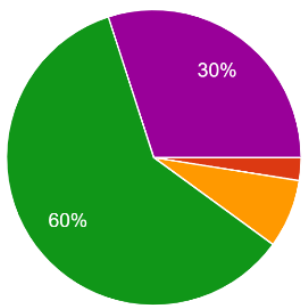

Discordo totalmente

Discordo

Não concordo, nem discordo

Concordo

Concordo totalmente

Fonte: Kochhann, Castro, Severo e Borges. (2021)

Figura 4 - As medidas de distanciamento social impactaram a organização e a Convivência em sociedade. As medidas também impactam a realidade do Campus Oeste?

4. As medidas de distanciamento social impactaram a organização e a convivência em sociedade. As medidas também impactam a realidade do Campus Oeste? 80 respostas

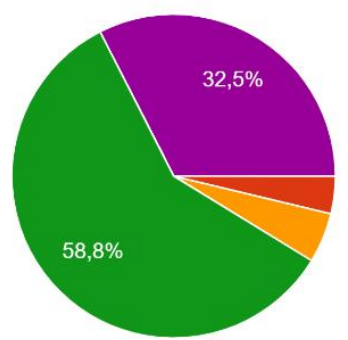

Discordo totalmente

Discordo

Não concordo, nem discordo

Concordo

Concordo totalmente

Fonte: Kochhann, Castro, Severo e Borges. (2021)

Figura 5 - O não acesso à estrutura física do campus, em virtude das medidas de combate a covid-19, a exemplo do distanciamento social, interferiram na sua 
aprendizagem?

5. O não acesso à estrutura física do campus, em virtude das medidas de combate a covid-19, a exemplo do distanciamento social, interferiram na sua aprendizagem?

80 respostas
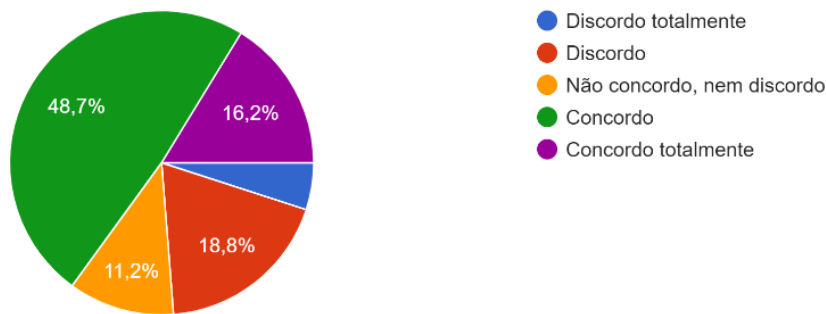

Fonte: Kochhann, Castro, Severo e Borges. (2021)

Os alunos sinalizaram para a perspectiva de mudanças efetivas na educação no Ensino Superior, bem como 77,5\% consideraram que a pandemia influenciou negativamente na qualidade do ensino aprendizagem ao qual tiveram acesso. $90 \%$ dos participantes percebem que houveram alterações na realidade, na organização e na convivência no Câmpus Oeste. Quanto ao não acesso a estrutura física do câmpus e a possível interferência na aprendizagem 48, 7\% concordam que houve prejuízo, para $16,2 \%$ concordam totalmente, neste quesito $18,8 \%$ discordam dessa possível interferências em sua aprendizagem, seguidos por $5 \%$ que discordam totalmente e 11,2\% que não concordam e nem discordam.

Com base nos dados percebe-se que, a pandemia alterou o sistema educacional, modificando a perspectiva de educação no Ensino Superior, bem como interferiu diretamente na vivência, no processo de ensino-aprendizagem e na realidade organizacional do Câmpus Oeste. Entretanto, uma parcela significativa dos colaboradores não identificam prejuízos em sua aprendizagem, o que instiga a reflexão acerca de uma possível autonomia academia e/ou, das condições materiais, de acesso a tecnologia, para continuação do ensino aprendizagem no ensino remoto ou ainda, que essa percepção seja reflexo de uma experiência prévia de educação mediada por tecnologias, o que seria comum no contexto da Educação 4.0.

\section{Ensino remoto}

O segundo eixo intitulado ensino remoto abarca as questões 6 a 9, nas quais questiona-se a percepção dos partícipes quanto às suas vivências no ensino remoto. 
Figura 6 - Quanto ao uso das Tecnologias da Informação e Comunicação (TIC's), domínio para utilização das plataformas e recursos você foi bem instruído/orientado?

6. Quanto ao uso das Tecnologias da Informação e Comunicação (TIC's), dominio para utilização das plataformas e recursos você foi bem instruido/orientado?

80 respostas

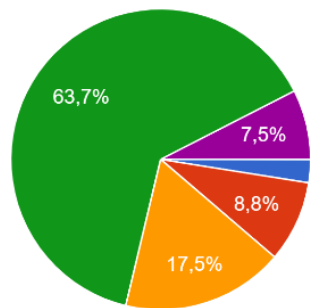

Discordo totalmente

Discordo

Não concordo, nem discordo

Concordo

Concordo totalmente

Fonte: Kochhann, Castro, Severo e Borges. (2021)

Figura 7 - A qualidade de sua internet interfere em seu acesso ao ensino remoto? 7. A qualidade de sua internet interfere em seu acesso ao ensino remoto? 80 respostas

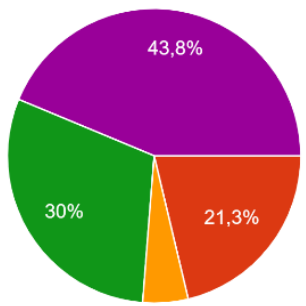

Discordo totalmente

Discordo

Năo concordo, nem discordo

Concordo

Concordo totalmente

Fonte: Kochhann, Castro, Severo e Borges. (2021)

Figura 8 - A qualidade da internet interfere no seu processo de aprendizagem? 8. A qualidade da internet interfere no seu processo de aprendizagem? 80 respostas

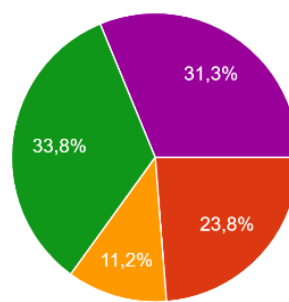

Discordo

Não concordo, nem discordo

Concordo

Concordo totalmente

Fonte: Kochhann, Castro, Severo e Borges. (2021)

Figura 9 - A qualidade da internet interfere na mediação do professor? 9. A qualidade da internet interfere na mediação do professor? 80 respostas

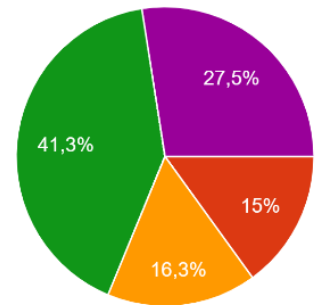

Discordo totalmente

Discordo

Não concordo, nem discordo

Concordo

- Concordo totalmente

Fonte: Kochhann, Castro, Severo e Borges. (2021) 
No contexto do ensino remoto, a utilização das Tecnologias da Informação e Comunicação (TIC's) são imprescindíveis. Portanto, é necessário que as Instituições de Ensino Superior (IES) instruam seus discentes quanto ao uso pedagógico das TICs. No Câmpus Oeste apenas $11,3 \%$ dos discentes sinalizam não terem sido orientados, ainda que a maioria dos participantes afirmam ter recebido alguma forma de orientação/instrução. A qualidade da internet é fator primordial para o bom andamento das aulas e consequentemente aprendizagem. Acesso, permanência, aprendizagem e mediação estão diretamente vinculados à qualidade da internet, conforme os partícipes.

A internet é fator primordial na perspectiva de Educação 4.0 e fator sensível no ensino remoto bem como, na realidade do sistema educativo brasileiro, pois vive-se na Era digital, na qual a utilização das tecnologias deveriam estar inseridas de modo contínuo nas ações mais corriqueiras. (FUHR, 2019) Todavia, os dados revelam o local crítico do acesso e da qualidade da internet, ainda presente na realidade educacional de diversos discentes, o que significa uma lacuna entre a real possibilidade de virtualização e o acesso ao conhecimento.

\section{Educação 4.0}

O terceiro eixo intitulado Educação 4.0, abarca as questões de 10 a 16, nas quais são abordados questionamentos sobre conceitos, utilização, influência na qualidade do ensino aprendizagem e na realidade dos discentes do curso de pedagogia.

Figura 10 - Quanto ao sentido de Educação 4.0, você compreende o termo?

10. Quanto ao sentido de Educação 4.0, você compreende o termo? 80 respostas
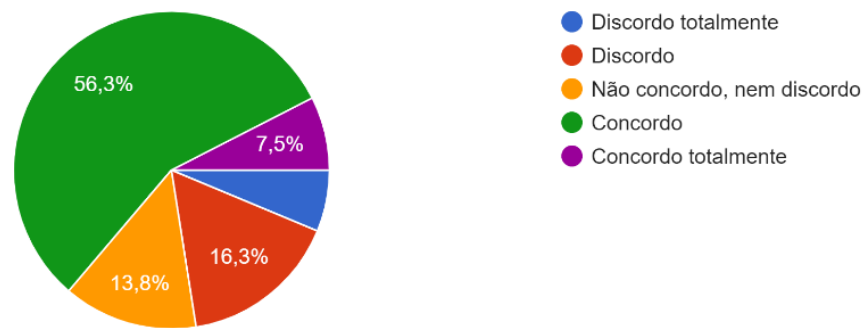

Fonte: Kochhann, Castro, Severo e Borges. (2021)

Figura 11 - A Educação 4.0 é uma realidade no seu context de estudo? 
11. A Educação 4.0 é uma realidade no seu contexto de estudo?

80 respostas

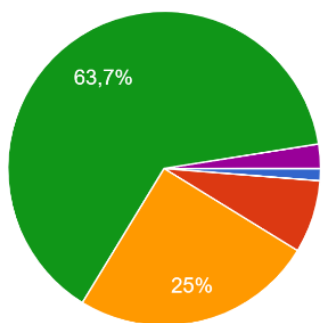

Discordo totalmente

Discordo

Não concordo, nem discordo

Concordo

Concordo totalmente

Fonte: Kochhann, Castro, Severo e Borges. (2021)

Figura 12 - A Educação 4.0 foi intensificada ao longo da pandemia. A educação mediada pelas tecnologias contemporâneas se consolidará após o contexto pandêmico?

12. A Educação 4.0 foi intensificada ao longo da pandemia. A educação mediada pelas tecnologias contemporâneas se consolidará após o contexto pandêmico?

80 respostas

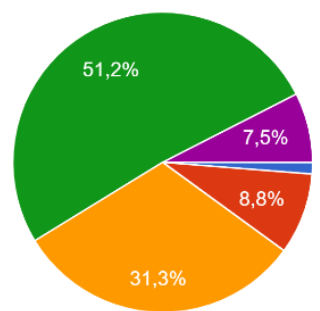

Discordo totalmente

Discordo

Não concordo, nem discordo

Concordo

Concordo totalmente

Fonte: Kochhann, Castro, Severo e Borges. (2021)

Figura 13 - Você considera que a pandemia prejudicou a qualidade do ensino aprendizagem?

13. Você considera que a pandemia prejudicou a qualidade do ensino aprendizagem?

80 respostas

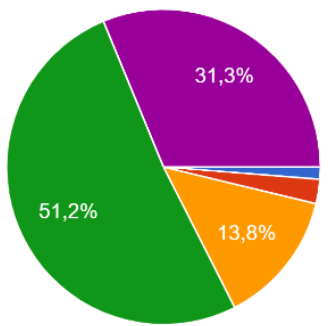

Discordo totalmente

Discordo

Não concordo, nem discordo

Concordo

Concordo totalmente

Fonte: Kochhann, Castro, Severo e Borges. (2021)

Figura 14 - A educação no contexto pós-pandêmico, se aproximará da perspectiva tradicionalista?

14. A educação no contexto pós-pandêmico, se aproximará da perspectiva tradicionalista?

80 respostas

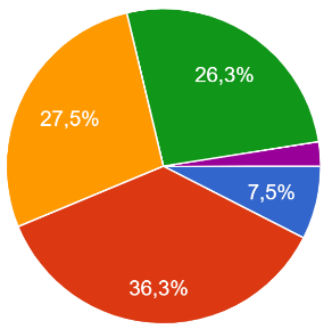

Concordo totalmente 
Fonte: Kochhann, Castro, Severo e Borges. (2021)

Figura 15 - Você considera que a pandemia impulsionou melhoria na qualidade do Ensino aprendizagem?

15. Você considera que a pandemia impulsionou melhoria na qualidade do ensino aprendizagem? 80 respostas
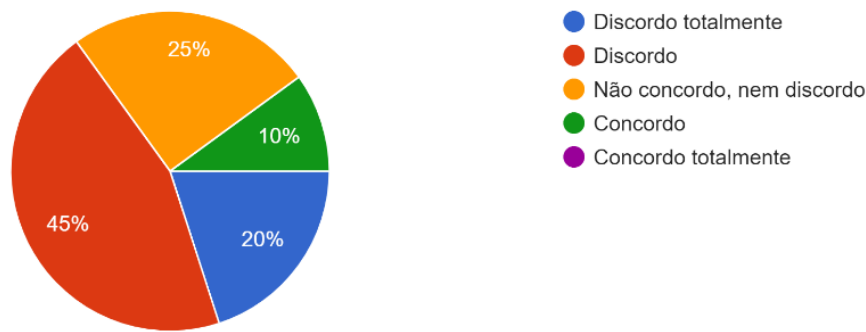

Fonte: Kochhann, Castro, Severo e Borges. (2021)

Figura 16 - O contexto pandêmico alterou as concepções de educação de modo a significar uma ruptura com a concepção tradicional?

16. O contexto pandêmico alterou as concepções de educação de modo a significar uma ruptura com a concepção tradicional?

80 respostas

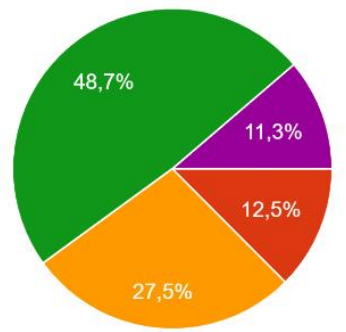

Discordo totalmente

Discordo

Não concordo, nem discordo

Concordo

Concordo totalmente

Fonte: Kochhann, Castro, Severo e Borges. (2021)

O termo Educação 4.0 é relativamente novo no meio acadêmico e em difusão, entretanto os dados revelam que os licenciandos em pedagogia possuem algum grau de familiaridade com o termo ou compreendem seu significado, 66,1\% dos partícipes afirmam que a educação 4.0 é uma realidade vivenciada no contexto do ensino superior do Câmpus Oeste, sede São Luís de Montes Belos. Ao serem questionados sobre a consolidação da Educação 4.0 na educação no período pós pandêmico, 51,7 \% sinalizaram concordar com esse cenário, enquanto $31,3 \%$, não concordaram nem discordaram, para $8,8 \%$, que discordaram dessa possibilidade.

A educação mediada pelas tecnologias digitais põe-se como necessidade no ensino remoto e no horizonte da educação para os próximos anos, ainda que as tecnologias possibilitem as mediações pedagógicas ou mesmo o processo de ensino aprendizagem, $82,5 \%$ dos partícipes apontam para os prejuízos da pandemia no ensino aprendizagem. Mas isso não resultará em uma aproximação com uma perspectiva tradicionalista de 
educação para 43,8\% dos partícipes, o que revela um otimismo para a presença e progressão da tecnologia na educação, uma ruptura com o analógico.

Embora o ensino remoto possa se apresentar superficialmente como constituinte da Educação 4.0, é necessário localizá-lo no contexto emergencial da pandemia, no qual se insere como ferramenta paliativa aos dados da conjuntura. Ainda que o uso das TIC's tenha incitado a ideia de qualidade no ensino aprendizagem, tal pressuposto não se legitima segundo $65 \%$ dos pesquisados.

O que por sua vez significa uma ruptura com a concepção tradicional de Educação para $60 \%$ dos partícipes. Assim, torna-se possível asseverar que a Educação 4.0 emerge neste contexto, como possibilidade com vistas a uma realidade educativa já, no contexto pandêmico. No entanto, isso pode também sinalizar o desconhecimento acerca do assunto e que na tentativa de se ver livre do questionário, ou aparentar inteirado (a) no que tange ao mesmo, as respostas sinalizam mais que dizem.

\section{Considerações}

A pandemia de covid-19 colocou o mundo em um cenário de crise no qual todos os setores (econômicos, políticos, sociais entre outros) foram drasticamente afetados pelo número de doentes e, por consequência, pelas medidas de combate que incluíram o fechamento de instituições públicas e privadas - lockdown - para evitar aglomerações e contaminação dada a necessidade de distanciamento social.

Esta pesquisa investigou esse cenário pandêmico do ponto de vista do ensino remoto, modalidade de ensino emergencial adotada como possibilidade imediata de continuidade das atividades de ensino aprendizagem em todos os níveis educacionais, mas especificamente nessa relação com o Ensino Superior partindo da percepção dos discentes da UEG (SLMB) do curso de Pedagogia.

A pandemia afetou diretamente a vida e percepção dos alunos do curso de Pedagogia da UEG (SLMB). O contexto de pandemia interferiu na qualidade do ensino aprendizagem ofertado, bem como na mediação pedagógica, isto quando olhamos sob o prisma do acesso tecnológico, da qualidade da internet dos discentes, da preparação e instrução para uso pedagógico das TIC's.

A presença significativa e necessária da tecnologia na universidade possibilitou a continuação das investigações, das pesquisas e das propostas pedagógicas e os dados 
coletados revelam que a Educação 4.0 tem sido propagada e sua relação com a pandemia, incorrendo em um rompimento com uma tendência tradicional de educação, o que possa ser resultado da cibercultura na qual os discentes já vivenciavam ou passaram a vivenciar dada a pandemia. Porém, muitas questões precisam ser consideradas quando se aborda a Educação 4.0, principalmente no tocante ao atendimento do neoliberalismo. Quiçá, discussão de um próximo texto.

\section{REFERÊNCIAS}

Ali, W. Online and Remote Learning in Higher Education Institutes: A Necessity in light of COVID-19 Pandemic. Higher Education Studies, 10(3). 2020. Recuperado de https://doi.org/10.5539/hes.v10n3p16.

BERTOLINI, R. O ecossistema de aprendizagem e a nova IES. In: REIS, F. (Org). Revolução 4.0: a educação superior na era dos robôs. 1. ed. São Paulo: Cultura, 2019.

BEZERRA, K. P. et al. Ensino remoto em universidades públicas estaduais: o futuro que se faz presente. Research, Society and Development, [S. l.], v. 9, n. 9, p. e 359997226, 2020. DOI: 10.33448/rsd-v9i9.7226. Disponível em:

https://rsdjournal.org/index.php/rsd/article/view/7226. Acesso em mar. 2021.

BRASIL. Ministério da Educação. Portaria no 343, de 17 de março de 2020. Dispõe sobre a substituição das aulas presenciais por aulas em meios digitais enquanto durar a situação de pandemia do Novo Coronavírus - COVID-19. DOU - Imprensa Nacional [Internet]. Recuperado de Recuperado de http://www.planalto.gov.br/CCIVIL_ 03/Portaria/PRT/Portaria\%20n\% C2\%BA\%20343-20-mec.htm.

CESAR, S.B. A indissociabilidade ensino, pesquisa, extensão e a gestão do conhecimento: estudo em universidade brasileira. 2013. 43f. (Dissertação - Mestrado em sistemas de informação e gestão do conhecimento) - Universidade FUMEC/FACE. Belo Horizonte, Minas Gerais, 2013.

CUNHA, L.A. Qual universidade? São Paulo: Cortez, 1989.

FIGUEIREDO, H. Quarta revolução industrial: desafios para o ensino superior. In: REIS, F. (Org). Revolução 4.0: a educação superior na era dos robôs. $1^{\circ}$ ed. São Paulo: Cultura, 2019.

FUHR, R. C. Educação 4.0 nos impactos da quarta revolução industrial. $1^{\circ}$ ed. Curitiba: Appris, 2019.

FUHR, R.C. Educação 4.0 e seus impactos no século XXI. V Congresso nacional de Educação - CONEDU, 2018. Disponível em: https://editorarealize.com.br/editora/anais/conedu/2018/TRABALHO_EV117_MD4_S A19_ID5295_31082018230201.pdf. Acesso em março de 2021. 
GATTI, B. A. Estudos quantitativos em educação. Educação e Pesquisa, São Paulo, v. 30, n.1, p. 11-30, jan./abr. 2004.

GIL, A. C. Métodos e técnicas de pesquisa social. 6. ed. São Paulo: Atlas SA, 2008.

LEVY, P. Cibercultura. 3. ed. São Paulo: Editora 34, 2014.

LIKERT, R. A Technique for the Measurement of Attitudes. Archives of Psychology, v. 140, 1932.

KOCHHANN, A. Desenvolvimento Curricular do Curso de Pedagogia da UEG (2000-2010) [manuscrito]. Goiânia, 2013. Disponível em:

http://tede2.pucgoias.edu.br:8080/bitstream/tede/1100/1/ANDREA\%20KOCHHANN\% 20MACHADO.pdf. Acesso em fev. de 2021.

MORAIS, R. R., MONTEIRO, R. Indústria 4.0: impactos na gestão de operações e logística. São Paulo: Editora Mackenzie, 2019.

PHILBECK, T. A educação em nova era. In: REIS, F. (Org). Revolução 4.0: a educação superior na era dos robôs. São Paulo: Cultura, 2019.

RASQUILHA, L. e VERAS, M. Educação 4.0: o mundo, a escola e o aluno na década 2020-2030. São Paulo: Unitã, 2019.

UEG. UNIVERSIDADE ESTADUAL DE GOIÁS. CÂMPUS Oeste - Sede: São Luís de Montes Belos. Disponível em:

http://www.campusoeste.ueg.br/conteudo/9589_historia. Acesso em março de 2021.

VIEIRA. S. L. A democratização da universidade e a socialização do conhecimento. In: FÁVERO, M. L (Org).Universidade em questão. São Paulo: Cortez, 1989.

Recebido em: 01/12/2021

Aprovado em: 20/12/2021

Publicado em: 23/12/2021 